Journal of Humanities, Social and Management Sciences (JHSMS)

eISSN: 2788-4791 (online)

https:// doi.org/10.47264/idea.jhsms/2.2.20

Vol. 2, No. 2 (July-December 2021), 285-301

https://www.ideapublishers.org/index.php/jhsms

Research Article

\title{
Factors limiting optimal students' engagement on Social Media: A study of Higher Education Institutions in Pakistan
}

Muhammad Awais Mehmood $^{1}$ Qaiser Rashid Janjua*2 | Muhammad Ali Saeed ${ }^{1}$ | Hina Samdani ${ }^{1}$

1. Bahria Business School, Faculty of Management Science, Bahria University, Islamabad, Pakistan.

2. School of Management, Faculty of Administrative Sciences, Air University, Islamabad, Pakistan.

*Corresponding Author Email: qaiser.janjua@ mail.au.edu.pk|qrj786@gmail.com

Received: September 14, 2021

Published: December 31, 2021

\begin{abstract}
Limited research on Social Media (SM) marketing by Higher Education Institutes (HEIs) primarily focuses on understanding important practices followed to enhance students' engagement on SM or its association with different branding constructs. However, there is dearth of research that can guide regarding practices negatively influencing SM based communication between HEIs and Students. This research explores these limiting factors affecting optimal students' engagement on SM. A qualitative exploratory research methodology was adopted based on in-depth interviews and Netnography. 25 interviews were conducted and 6 months content analysis of Facebook account of selected HEIs was carried out for Netnography. The findings revealed different content and non-content factors negatively influencing students' engagement on SM. Content related factors included poor design of SM content, lack of informality, inconsistent content posting and content posting during office hours. Whereas noncontent related factors include selective platform presence, selective response to students' queries, fearful attitude towards official SM and absence of incentives for students to engage on SM. All these factors are believed to affect different stages of Customer Engagement including Connection, Interaction, Loyalty and Advocacy. Findings of this study have enabled gaining empirical knowledge regarding negative practices on SM, highlighted above, that shall be avoided to attain optimal results for SM marketing communication and learning how these practices affect different stages of students' engagement on SM.
\end{abstract}

Keywords: social media, social media marketing, higher education institutes, customer engagement, connection, interaction, loyalty, advocacy, Netnography.

How to Cite: Mehmood, M. A., Janjua, Q. R., Saeed, M. A., \& Samdani, H. (2021). Factors limiting optimal students' engagement on Social Media: A study of Higher Education Institutions in Pakistan. Journal of Humanities, Social and Management Sciences (JHSMS), 2(2), 285-301. https://doi.org/10.47264/idea.jhsms/2.2.21

Publisher's Note: IDEA PUBLISHERS (IDEA Publications Group) stands neutral regarding jurisdictional claims in the published maps and institutional affiliations.

Copyright: ( 2021 The Author(s), published by IDEA PUBLISHERS (IDEA Publications Group).

Licensing: This is an Open Access article published under the Creative Commons AttributionNonCommercial 4.0 International License (http://creativecommons.org/licenses/by-nc/4.0/) 
Factors limiting optimal students' engagement on Social Media: A study of Higher Education ...

\section{Introduction}

Social Media (SM) based communication has engraved itself into daily life of people (Jacobson, Gruzd, \& ÁngelHernández-Garcíac, 2020). Organizations also rigorously adopt and use this technology for daily communication needs and marketing purpose (Razak \& Latip, 2016). HEIs are no different in this regard are actively embracing SM to engage with their stakeholder (Xiong, et al., 2018). It is perceived to be less intrusive versus traditional marketing communication options, which easily blends in with daily communication feed (Molenaar, et al., 2021). It provides organizations an informal platform of connecting with their customers who are living a virtual life (Tiago \& Verı'ssimo, 2014). According to Aristotle, all beings are subject to some form of representation (McKeon, 1973). This representation is mediated through various means and in case of digital technologies; it is SM platforms, giving individuals an opportunity to represent themselves as virtual beings. Teen and young adults are believed to spend an average 1 hour per day on SM (Rideout \& Fox, 2018). An average Pakistani is spending approximately 2.5 to 3.5 hour on internet daily, including time spent on SM platforms (Suhail, 2019). These statistics clearly shows the value, brands see, in communication via SM.

Adoption of SM for marketing communication purpose is not specific to any particular industry. Past studies highlight SM adoption in several industries such as sports, telecommunication, healthcare, banking sector, etc. (Lagrosen \& Josefsson, 2011; Lagrosen \& Grunden, 2014; McCarthy, Rowley, Ashworth, \& Pioch, 2014; Eagleman, 2013; Tsimonis \& Dimitriadis, 2014). The adoption of SM for communication purpose is also not a new phenomenon for Higher Education Institutes (HEIs) (Dabner, 2012; Mehmood, Janjua, Akram, Laeeque, \& Aftab, 2021). Almost every University seems to have some form of SM presence to communicate with their target audience. There is an increasing trend of recruiting dedicated teams to manage SM based communications, highlighting the investment of money and time being made by HEIs to communicate through SM (Mehmood, Janjua, \& Saeed, 2021). This trend also shows the confidence educational institutes have developed with this form of communication in terms of its reach and efficacy. Recent research on SM marketing has tried to understand various marketing perspectives of SM and associated benefits with use of SM (Hoffman \& Fodor, 2010; Kim \& Ko, 2010; Michaelidou, Siamagka, \& Christodoulides, 2011; Sashi, 2012; Hudson \& Thal, 2013; Nadaraja \& Yazdanifard, 2013; Stephen, 2016; Zollo, Filieri, Rialti, \& Yoon, 2020; Ali \& Xiaoying, 2021).

The literature also highlights factors influencing HEIs to adopt SM for communication purpose (Mehmood, et al., 2021). But adoption of any technology for communication purpose is merely a first step towards an active engagement that brands are striving to achieve. Customer engagement on SM is an understudied phenomenon (Shawky, Kubackib, Dietricha, \& Weavena, 2020), especially in context of HEIs. Limited literature in this domain mostly focuses on understanding factors positively contributing towards customer engagement (Riley, 2020; Alalwan, et al., 2020; Lei, Pratt, \& Wang, 2017; Jayasingh \& R.Venkatesh, 2015). But there is dearth of research that has tried to highlight factors negatively affecting customer engagement on SM for a clearer understanding regarding do's and don'ts of SM based marketing communication. This research has therefore tried to fill this gap by identifying content and noncontent related factors of SM, which are believed to limit optimal utilization of SM by Pakistani HEIs. These limiting factors were analyzed through the customer engagement framework of SM presented by (Shawky, Kubacki, Dietrich, \& Weaven, 2020) to understand effect of various 
limiting factors across different stages of customer engagement.

\subsection{Purpose of research}

SM has weaved itself into daily lives of people and becoming a prominent option of communication by brands. HEIs are also maintaining their SM presence and posting information on multiple SM platforms for sharing with their stakeholder. There are clear efforts showing attainment of active customer engagement on SM to reap full benefits of a costeffective marketing communication option. But these efforts are being made without understanding factors, which may negatively impact customer engagement on SM. Knowledge about these factors can help better understand the do's and don'ts of SM marketing communication, especially in context of HEIs. This research has focused on following two objectives:

a) Identify factors that are believed to negatively influence students' engagement on SM.

b) Learn about the negative influence of identified factors across different stages of customer engagement on SM.

\subsection{Conceptual framework}

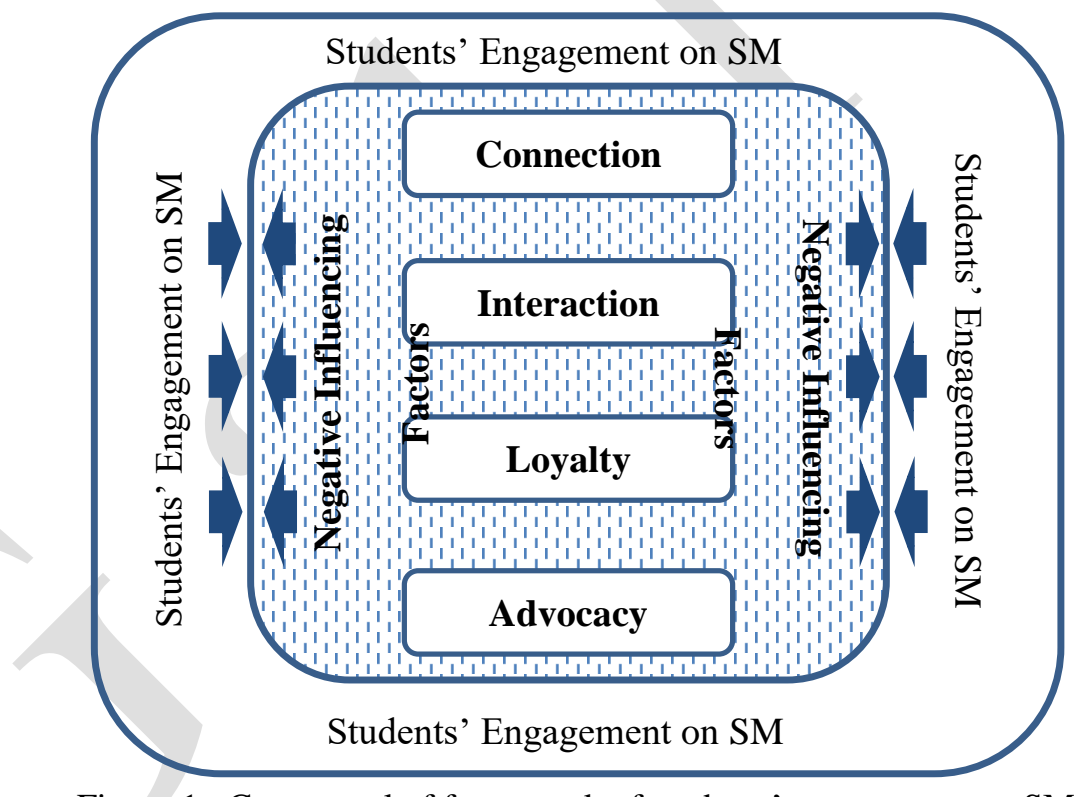

Figure 1: Conceptual of framework of students' engagement on SM

\section{Literature review}

The fast-changing technology has reshaped the way people used to interact with the brands in past. There were limited options before in terms of brand communication, but now digital technologies have increased this interaction many folds (Farook \& Abeysekara, 2016). Online communications technologies have somewhat become the most important mean of learning about a brand and its performance. Despite its complexities, limitations and ethical concerns it is quite visible that brands have started living an e-life. ICT has become the most commonly used medium to communicate (Mingers \& Willcocks, 2017). Traditional media such as 
Factors limiting optimal students' engagement on Social Media: A study of Higher Education ...

newspaper, billboards and TV have perhaps lost their supremacy, which they have enjoyed for years, especially for higher level of customer engagement with young consumers. Information regarding brands is being pulled from digital media rather than being pushed, as in the past (Wind \& Mahajan, 2002; Batool, Iftikhar, \& Mashal, 2020). People are relying less on what the brands have to say about themselves and more on what others have to say. The digital media, primarily through Web 2.0 based technologies, has given a strong voice to those customers. Using internet technologies, the customers are obtaining real time information about the brands and what their customers have to say (Mehreen et al., 2020).

With growing value of SM based communications, brands are putting more efforts to actively engage with their customers on SM based platforms. It is therefore research on customer engagement on SM based communication is gaining more value (Santini, et al., 2020; Jayasingh \& Venkatesh, 2015). According to Shawky et al (2020), customer engagement on SM platforms revolves around four pillars including connection, interaction, loyalty and advocacy. While connection is considered a pre-requisite of any form of customer engagement on SM, but the remaining pillars by no mean define a must go-through process to achieve engagement. However, focus on all constructs of this framework provides a sequential leader, which if followed, can lead towards a more natural form of active customer engagement on SM platforms.

Connection is considered to play a fundamental role towards active customer engagement on SM. It is seen as stimuli that attracts customers towards SM based communication with brands. According to Hansen, Shneiderman, \& Smith (2011), SM has enabled billion of users to develop trillion of connections. These connections ultimately help build relationships and allow organizations to tap into their customers' world where they were not allowed to tread before (Hanna, Rohm, \& Crittenden, 2011). People seek membership of social networks to fulfill their need of social connection for interaction, entertainment, relaxation, passing time or seeking information (Riley, 2020). Brands make such connections possible with their stakeholders by creating their SM presence and actively posting content on SM. It is one-way stage of communication on this interactive platform that sets the stage for active customer engagement. Customers are more encouraged to connect with networks where their peers are also present (Shawky, et al., 2020).

Connection is followed by a two-way communication stage i.e., interaction. At this stage, customers are believed to more actively contribute by active posting of comments, giving feedback and by sharing and liking SM content. According to Shawky et al (2020), customers are not willing to interact with posts that have no social contribution. Customers prefer interacting with posts that can highlight benefits for others, showing the social side of SM based communication. According to Holt (2016), brands shall actively listen-in for developing trends (memes) on SM platforms, which are forming short lived subcultures. Subcultures are generally defined as "a relatively diffuse social network having a shared identity, distinctive meanings around certain ideas, practices, and objects, and a sense of marginalization from or resistance to a perceived conventional society" (Haenfler, 2013). SM has expanded these subcultures. These subcultures exist around almost any set of topics and are just one click away, forming crowd cultures with the convenience of SM. Brands succeed in achieving active interaction if they appeal to their crowd cultures and SM is enabling organizations to listen to these cultural opportunities, target the crowd culture and diffuse the new ideology (Holt, 2016). It is therefore important for organizations to understand those crowd-cultures within their SM 
reality that can allow their content to be more actively shared and circulated amongst their users for enhanced interaction.

Enhanced interaction is believed to lead towards the stage of Loyalty, which is an elevated stage of customer engagement on SM (Shawky, et al., 2020). At this point, customers develop a special bond with brands to more actively interact with them and with other customers, forming online communities. Laroche, Habibi, Richard, \& Sankaranarayanan (2012) in their research showed a strong connection between formation of online communities using SM with development of brand trust and loyalty. This formation of communities and sub communities matches with the concept of brand communities that is defined as a "specialized, nongeographically bound community, based on structures set of social relations among admirers of brand" (Muniz \& O'Guinn, 2001). The formation of communities on SM can be obviously much larger in scale due to technology and can therefore be termed as special brand community with its own set of dynamics. Yet, at the same time, it is very similar to a greater extent with regular brand communities showing all the indicators including consumers' relationship with brand elements and value creation practices (Habibi, Larochea, \& Richard, 2014). There exist many examples of companies using group functionality of SM (Kietzmann, Hermkens, McCarthy, \& Silvestre, 2011) to better connect with their customers. Some examples in this regard quoted by Chu (2011) include Facebook group pages: (a) Tide Loads of Hope; (b) Sony Digital Photography; and (c) Dodge, It's a Way of Life.

All above group pages allow the brand community of these brands to share pictures, videos and other content types to stay connected with their brand and forming stronger brand communities. According to Shawky et al (2020), to achieve such loyalty, organizations can offer incentives, rewards, run promotions and give positive gestures such as thanking customers and acknowledging their contribution on SM. According to Keitzmann et al (2012), individuals are motivated by intrinsic and extrinsic motivators to share content on SM. Intrinsic motivation is a type of motivation that is natural to a person and pushes them to act with zeal in order to acquire personal pleasure, self-satisfaction, peer acknowledgment, overcoming curiosity, or a sense of challenge. Extrinsic motives are linked to external rewards that one eye to receive as a result of engaging in a certain activity. People in SM can be seen interacting and sharing content based on their intrinsic and extrinsic motives. Provision of incentives, rewards and promotions (Shawky, et al., 2020) perhaps provide customers to have extrinsic motivations (Keitzmann, et al., 2012) to more actively engage on SM.

The stage of loyalty is followed by highest level of engagement called advocacy. This is the point where customers encourage other customers to engage with the organization and their content on SM. This is achieved through co-creation of value by sharing own experiences and stories on SM and actively sharing content on their timelines (Shawky, et al., 2020). Such advocacy and active engagement through sharing of own experiences may get affected due to privacy concerns on SM. According to Athukorala (2018), students' engagement through SM is negatively influenced due to privacy concerns, especially in countries such as China. So apart from developing connection, enhancing interaction and nourishing loyalty, HEIs perhaps need to overcome privacy concerns of their students to encourage them to freely share their experiences and stories to co-create value and become brand advocates.

The reflection of advocacy can also be seen on SM in form of active participation by customers to help and assist other customers based on their knowledge, experiences and person opinions 
Factors limiting optimal students' engagement on Social Media: A study of Higher Education ...

(Shawky, et al., 2020). This can be equated to a customer service delivered by customers for other customers. It is perhaps correct to presume that the customer service, which plays an important role towards brand building, has remodeled itself on SM to include 'inter-customer support' due to increased $\mathrm{C} 2 \mathrm{C}$ communication. Now if you put any query regarding a product or service on SM, other customers would jump in to assist, guide and communicate with you to share their knowledge and experiences. This inter-customer support has been in existence for years in case of online business or IT based solutions but has expanded to include off-line businesses due to the online presence of that company and their customers on SM (Sigala, 2009). It is pertinent to mention that there is no compulsion for a customer to become advocate after passing through the stages of interaction and loyalty. At times, simple connection can result into customer sharing content of any organization on SM. But it is important for organizations to encourage their customers go through these different stages to achieve consistency in their advocacy on SM.

According to Shawky et al (2020), movement across different stages of the customer engagement framework on SM is dependent on customers' satisfaction. Santini et al (2020) explained this satisfaction with the concept of positive emotions, which collectively mediates the journey towards active customer engagement on SM. Satisfaction, is seen as a result of positive cognitive evaluation of consumption outcomes resulting into positive emotions such as enthusiasm, freedom of expression and positive outcome expectation. The feeling of satisfaction and positive emotions positively influence customer engagement on SM platforms. If the customer is not satisfied with any of these stages, there is an increased probability that they will move back in stages or simply disassociate themselves from engaging with such organizations (Shawky, Kubackib, Dietricha, \& Weavena, 2020). It will therefore be interesting to learn about the factors, which are believed to contribute towards dissatisfaction or negative emotions of students to engage more actively on SM, resulting into a lower engagement level.

\section{Research methodology}

Official adoption of SM by Pakistani HEIs for marketing communication is a comparatively new phenomena, which is not more than 7-8 years old (Mehmood, Aftab, \& Mushtaq, 2016). The knowledge regarding optimal utilization of this communication option is still evolving, based on experiential knowledge gained by different stakeholders involved. To develop understanding regarding an evolving phenomenon, an exploratory study is recommended to learn from the experiences of those who are living the reality (Denzin \& Lincoln, 2005). This research has therefore employed qualitative research methodology based on data collection methods of In-depth Interviews and Netnography. A total 25 interviews were conducted from the relevant stakeholders of SM based communication in HEIs. This included SM managers, who were responsible for the management of SM and students, who were engaging with their HEIs using SM platforms. The students and SM managers were from seven selected HEIs of Pakistan, which were selected on bases of their active SM presence, in terms of number of followers and likes. These HEIs were based in four cities of Pakistan with the most active SM usage (Qureshi, 2016) i.e., Karachi, Lahore, Islamabad and Peshawar. In addition to the indepth interviews, data of 6 months usage of SM platforms of the existing HEIs was analyzed to understand their execution of SM based marketing communication. While the selected HEIs showed presence on multiple platforms such as Facebook, Instagram, Twitter and LinkedIn, etc., but the most commonly used active SM platform was Facebook, which was then selected 
for observation of 6 months content of the selected HEIs. The data collected through in-depth interviews and Netnography was analyzed using NVivo 11 software to look for emerging themes that can help address the research objectives.

\section{Data and analysis}

The outcomes of SM usage reflected in literature shows a strong role it plays towards strengthening brands. But all these outcomes revolve around the concept of students' engagement (customer engagement). If there is no one to engage with the SM content of HEIs; the perceived outcomes will only remain as myths. It is therefore considered important to highlight any inhibiting elements towards optimal utilization of SM. These were broadly categorized into content related factors and non-content factors. Table highlighting identified themes is listed below:

\subsection{Contact factors}

\subsubsection{Poorly designed content}

The SM managers highlighted two important factors in their content design namely, the information and the information delivery. In terms of information, few SM managers suggested that putting down simple facts does not attract students' attention on SM. It is therefore they try to build stories around these facts so that students can more easily relate to them. As said by a SM manager:

"The university has swimming pool; it has medication spots and world class labs. And now if I only put simple pictures of these labs then I don't think so anyone will engage with us through such SM content. But instead, I show a child inside that lab, smiling and conducting an experiment making more sense for the target audience as they will be able to relate to the image. We create story around these facts of our university to make it more interesting and relevant for the audience to better connect with them."

The same practice was not visible in the SM content of majority of the selected HEIs. Several students highlighted that there HEIs were mainly sharing facts, which were not very appealing for them. According to Laroche et al (2012), sharing of stories on SM is believed to support formation of brand communities where customers can engage more with stories rather simple facts. The same perhaps stand true for students' communities on SM that connect more with content communicating stories of people they know or from the same community. Formation of brand communities through SM is reflection of utilization of group building block of honeycomb framework suggested by Keitzmann et al (2011). Utilization of this building block therefore can be seen contributing towards strengthening the bond between the HEIs and the students. HEIs need to make more of such functionalities of SM framework by putting content that supports strengthening of brand communities. The more HEIs will make their content revolve around real stories, and not mere facts, more it is believed to attract their students' community. Similar requirement of content has been demanded by students as follow:

"Then what is most important is that universities shall try to create stories around the facts they share on SM. e.g., put a picture of a guy from cafeteria 
Factors limiting optimal students' engagement on Social Media: A study of Higher Education ...

and put his story on SM. We will connect on SM through that person. The university therefore needs to leverage such personalities and such stories to engage more students."

Further, according to some students interviewed, the information shared shall be linked to ongoing trends on SM. This supports the concept of crowdcultures on SM suggested by Holt (2016). Due to short lived duration of the content on SM, even the trends have been termed as short-lived cultures. His recommendation is in line with what few SM managers suggest for content designing. As said by a SM manager:

"We also try to convey our message by wrapping it around some on-going trend, or meme of SM. For example, recently there was a mannequin challenge trend, and we also did the same and made a video of a mannequin challenge to make it more interesting and appealing for the customers."

In terms of content delivery, it has been observed in netnography and also based on the input of students and SM managers that video content had the highest engagement level. In the daily SM feed of some of the selected HEIs, there were several posts, with long textual content followed by static graphics (e.g., pictures, banners, news clippings). Such posts generally showed lowest engagement in terms of number of likes, shares, and comments. A SM manager said that live content on Facebook is becoming an important way to communicate on SM. According to him:

"If I put a simple image with a message, it may not attract many people on SM but if I go live on Facebook and post the same, I can expect to have more following."

\subsubsection{Lack of informality}

SM managers and students see SM as an informal communication mean. The findings have highlighted high-level of formality that some HEIs are bringing in an informal communication media. This formality is reflected through excessive posting of content containing images of senior management, formal group pictures, use of formal languages as if writing official letters and apparently pre-defined formal replies to students' queries. Some students interviewed told that they prefer going on unofficial SM accounts of the university, versus official account, primarily for the level of informality they offer. Unofficial accounts seem to understand students' communication tone better, as students are managing them. These are informal communications with interesting stories about their universities. HEIs need to perhaps take a lead from such unofficial accounts. A suggestion in this regard was given by a SM manager where he recommended a collaborative model between unofficial and official account. Both can leverage each other's strength to maintain good engagement level of the students.

A formal communication on SM more strongly reflects image of control that perhaps discourage students to engage. But according to the students' interviewed, SM accounts shall not project a very formal image. This is not an impossible thing to achieve. The only important element here is to educate the senior management of HEIs to make them understand language tone on SM versus print media. Both cannot be equated and shall not be equated. A SM manager quoted an example to explain this: 
"We see that happening in case of [School Name]. They have taken away the level of formality from their SM pages to remove the perception of controlled media, even though it is. And perhaps we and many other institutes can do the same. So, I know that my boss will not be comfortable with me posting selfies on SM."

\subsubsection{Inconsistent content posting}

Several students highlighted absence of regular updates on the SM pages of their HEIs making them lose track of university updates and consequently interest in pursuing communication on SM with their HEIs. According to some students, when they do not see daily feed on SM from their HEIs, it makes them wonder if they are still present or even considering using SM for their communication purpose. As said by a student:

"Once, our university did not update the content on SM for several days. I thought that maybe they have either switched from the existing SM platform or have decided not to pursue communication any more on SM. So, I stopped actively following their SM activity."

Another student explained it from a different perspective:

"One thing that puts me off to remain connected on SM with my University is its inactive approach in terms of content posting and responding to queries. It makes SM pages look dull, outdated and abandoned"

Some SM managers mentioned that they try to make it a point to at least put one post on SM to remain active on their selected SM platforms. But few also suggested that there is more active presence required on part of their university to constantly update their SM feed. To overcome this challenge, one University shared a practice where they have made multiple SM accounts for each Academic and Administrative Departments and given them authority to update their own content. While this takes away a centralized control mechanism but allows them to select from a wide pool of SM content related to their university and post it on University's main SM accounts regularly.

\subsubsection{Content posting during office hours}

Some SM managers interviewed highlighted a challenge of content posting during off-working hours and on weekends. According to them students are more active during evening or nighttime on SM. Similarly, they are spending more time on SM platforms on weekends. But it becomes difficult to engage the SM team to update content after office hours, especially in case of female employees. Few students also highlighted this issue. A student said:

"While my university regularly updates content on SM, but I see them posting content during morning or working hours. I think they shall have more regular update in evening, at nighttime or weekend as several times, a content posted during day hours gets scrolled down in my SM posts resulting into missing out on several University activities and announcements" 
Factors limiting optimal students' engagement on Social Media: A study of Higher Education ...

Mostly SM managers highlighted a strategy where the content designing was done during office hours and posting at night. But in HEIs where SM based communication is still evolving, there was recognition of this challenge and limitation towards optimal utilization of SM.

\subsection{Non-content factors}

\subsubsection{Selective platform presence}

According to students, while they were happy to see presence of their HEIs on multiple SM platforms, but the level of activeness across different platforms was not homogenous. This discouraged them to connect with their HEIs on SM as they were not able to view or share content on platforms, which are of relevance and interest to them. The same point was raised by some SM managers, from the perspective of lack of willingness of their management to invest on SM Affairs and to hire more staff to manage SM communication. According to these managers, the existing staff enables them to manage only a limited number of SM accounts actively. Managing SM communication is like a $24 \mathrm{hrs}$ responsibility where one has to stay on constant alert to respond to any query and remain engaged. While HEIs may be able to post content on multiple SM platforms but to manage queries and engagement on all SM platforms becomes a challenge with existing resource. A student explained this as follow:

"My university is active on Facebook, and I can see them regularly posting content on Facebook about our University activities. But I am unable to see same activeness on Instagram, Twitter or LinkedIn. This puts me off as many of my friends are more active on other platforms."

According to some students SM, for their HEIs, is "Facebook only". In terms of customer engagement, this limitation seems strongly associated with the concept of connection (Shawky, et al., 2020). Limited options of connectivity on multiple SM platforms, limits the options of connectivity students may have to actively engage with their HEIs, causing dissatisfaction at the very early stage, which has been highlighted as an important pre-requisite to move across different stages of customer connectivity.

\subsubsection{Selective response to students' queries}

Although HEIs state SM as a forum that allows them to easily manage students' queries, but the reality is perhaps not the same. The netnography data clearly shows that HEIs are only responding to less than $50 \%$ of the posted queries on their SM forum. This percentage will definitely vary from institutes to institute but does not show an active follow up on part of the HEIs. Some of the students' interviewed highlighted this as one of the discouraging factors in their SM communication with HEIs. Selective response is believed to discourage students to use this important forum as a mean of communication with HEIs. Some SM managers realize this importance and state as follow:

"SM has allowed us to more conveniently answer to students' queries. But at the same time, it is a big responsibility. If we even miss one query, it may end up having an unsatisfied student. His experience may get shared with other fellows discouraging many students to use this forum for communication purposes." 
There could be several factors that must be resulting into a selective approach of responding to students' queries but absence of good customer service culture in the country has been highlighted as one. According to some SM managers, HEIs need to have a more integrated approach in their marketing and develop a strong culture of good customer service off-line first and then use SM to compliment it.

Insufficient workforce has also been highlighted by several SM managers as a reason towards selective response towards students' query. They try to manage the most critical queries first and if the time permits, they then try to address other queries. The senior management of the HEIs has been inclined towards adoption of SM with the view that it will provide them a costeffective promotional mean. But the same influencing factor is perhaps also becoming a limitation and contributing towards non willingness to invest on SM affairs. Perhaps what HEIs need to understand is that while SM may be a more cost-effective promotional mechanism visà-vis its reach but cannot be run free. It is comparatively a cost-effective communication mean but cannot run on zero budget for organizational use.

\subsubsection{Fearful attitude towards official SM accounts}

Some students, while being interviewed, shared concern of being penalized by their respective HEIs in case if they place any negative comments on SM. This is believed to hinder true engagement of students with HEIs using this forum. HEIs need to somehow convince students that any feedback (positive or negative) will be valued on SM and through policies define SM communication boundaries. While swearing on SM communication can be arguable controlled but negative feedback reflecting a true opinion shall be encouraged. It will only then be possible to truly sense students' pulse to improve services. SM managers also seem to acknowledge this weakness of their official SM accounts. The lack of openness linked to high level of formality is resulting into students developing a fearful attitude towards official SM accounts. While this phenomenon may not apply to all the students but is definitely a matter of concern for HEIs and seen as hindering their optimal SM utilization. A SM manager, when asked about changing any one element of their existing SM practice stated as follow:

"One thing if I wish I can change about our existing practice of SM, it would be the level of openness. I wish students are given more leverage in speaking their heart out on SM. In fact, they should be encouraged to speak out openly on SM. Base on this openness we shall also try to bring general content which they generate at their self-created SM accounts. There shall be a small portion of such content to allow students engage more. We have seen in our university that students would be doing skits in front of university faculty and management in which they will make fun of some of the teaching styles or figures well known in student community. Faculty and management enjoy that as well and students love it as they are able to relate with it. Why can't we have this openness on SM?"

\subsubsection{No incentive for students}

While interviewing the students, they particularly highlighted absence of any direct (extrinsic) motivation for them to engage with their HEIs on SM. While they do acknowledge the benefit to stay abreast with important activities in their HEIs and convenience of obtaining answer to 
Factors limiting optimal students' engagement on Social Media: A study of Higher Education ...

their queries or sharing their thoughts on SM (intrinsic motivations) but are perhaps looking for more direct benefits to have the continued engagement with their HEIs on SM. The netnography data revealed that one institute was putting efforts in this direction where they were engaging their students by asking them to take their selfies next to a standee placed somewhere at campus and post it on Facebook, Twitter and Instagram account with hashtag \#LifeAt[Universit Name]. By doing this, the students were getting into a competition to win Rs.2,000/- for the best picture. Perhaps other HEIs need to take a lead from such actions to include direct incentives for students to engage on SM with their HEIs.

According to some students, absence of incentives can lead towards an inconsistent approach on their part to communicate with their HEIs on SM. They highlighted example of various loyalty programmes run by different retail outlets, where a loyalty programme is linked with some financial and non-financial incentives. Whether it is getting free points on loyalty cards or having access to other exclusive members' benefits; an incentive is believed to trigger interest and encourage consistent preference of a services. According to these students, HEIs are unfortunately not running such loyalty programmes for generating a more active participation and co-creation of value by their students on SM.

Table 1: Summary of qualitative themes

\begin{tabular}{|c|c|c|}
\hline $\begin{array}{l}\text { Broader } \\
\text { Themes }\end{array}$ & Themes & Sub-Themes \\
\hline \multirow{13}{*}{$\begin{array}{l}\text { Content } \\
\text { Factors }\end{array}$} & \multirow{4}{*}{$\begin{array}{l}\text { Poorly designed } \\
\text { content }\end{array}$} & Sharing of facts only \\
\hline & & Disengagement from ongoing trends \\
\hline & & Long textual information \\
\hline & & Static graphics (e.g., pictures, banners, news clippings, etc.) \\
\hline & \multirow{4}{*}{ Lack of Informality } & Excessive coverage of senior management \\
\hline & & Formal group pictures \\
\hline & & Formal write-ups \\
\hline & & Standard replies to students' queries \\
\hline & \multirow{3}{*}{$\begin{array}{l}\text { Inconsistent Content } \\
\text { Posting }\end{array}$} & Delayed updates \\
\hline & & Abandoned SM Pages \\
\hline & & Non-responsive Pages \\
\hline & Content posting & Non-availability of staff on weekends \\
\hline & during Office Hrs & Challenge in engaging staff in evening \\
\hline \multirow{12}{*}{$\begin{array}{l}\text { Non-Content } \\
\text { Factors }\end{array}$} & \multirow{3}{*}{$\begin{array}{l}\text { Selective Platform } \\
\text { Presence }\end{array}$} & Facebook Only \\
\hline & & Limited Human Resource to manage multiple accounts \\
\hline & & Lack of willingness to invest on SM \\
\hline & \multirow{3}{*}{$\begin{array}{l}\text { Selective Response } \\
\text { to Students' Queries }\end{array}$} & More than $50 \%$ unanswered queries \\
\hline & & Absence of good customer service culture \\
\hline & & Insufficient workforce \\
\hline & \multirow{3}{*}{$\begin{array}{l}\text { Fearful attitude } \\
\text { towards official SM }\end{array}$} & Concerns of being penalized for candid input \\
\hline & & Lack of openness \\
\hline & & High level of formality \\
\hline & \multirow{3}{*}{$\begin{array}{l}\text { No Incentive to } \\
\text { Engage on SM }\end{array}$} & Absence of extrinsic motivators \\
\hline & & Limited or no financial awards \\
\hline & & No loyalty programmes \\
\hline
\end{tabular}




\section{Discussion and findings}

Findings of this study have highlighted several content and non-content related factors, which are perceived to influence optimal students' engagement on SM. In terms of content factors, poorly designed posts are identified as a major demotivating factor by the participants. Students interviewed explained that poor design of SM was reflected where HEIs placed a lot of textual information on SM or used static graphics. Such posts were perceived as non-appealing, making SM trolling less entertaining and engaging. It was also highlighted that students do not engage with posts that contain facts only. They rather prefer real stories conveying benefits for others. All these elements are considered closely associate with the concept of interaction as per Customer Engagement Framework (Shawky, et al., 2020). To entice students towards active posting of comments, liking and sharing content, HEIs need to develop their SM content that is more appealing for students, showing clear benefits, to generate intrinsic motivation for them to engage on SM (Kietzmann, et al., 2012).

High level of formality on a platform, which is perceived as an informal mode of communication, is also believed to discourage students to engage more actively. Consistent posting of content with images of senior management, lack of spontaneous replies to queries, more group photographs than selfies, etc., were making students shift towards unofficial accounts, which matched their communication tone. This formality may be a requirement due to official nature of SM account but is perceived as a barrier towards generating active interactions and loyalty (Shawky, et al., 2020). Inconsistency in content posting by some HEIs and posting of content during working hours only was giving an impression of non-availability and making student disconnect from SM engagement with their HEIs. According to Riley (2020), people use SM for their social connections and an inconsistent content posting approach or posting content in times when students are not available may not enable them to achieve that social connection with HEIs through SM.

In terms of non-content related factors, absence of active presence of their HEIs on multiple SM accounts, was limiting options for students to actively connect with their HEIs on SM. This consequently created dissatisfaction at the early stage of customer engagement framework, inhibiting students to proceed to advance stages enthusiastically. Students highlighted nonactive presence of their HEIs on SM platforms where they usually have their friends circle. This according to Shawky et al (2020) is an important consideration when customers are connecting with any organization on SM. Selective response to students' queries by HEIs is also believed to discourage students to actively engage on SM. Just like in a regular social gathering, non-responsiveness discourages an individual to maintain or increase interaction, similarly non-responsiveness is believed to affect those students who are unable to obtain reply to their queries to maintain their interaction with their HEIs.

While there was a clear reflection in Netnography data that several students were actively engaging with their HEIs on SM through regular posting of content, sharing and liking different posts. However, these were apparently reflection of intrinsic motivations to connect with their HEIs on SM. But enhanced interaction, which according to Shawky et al (2020) is reflection of loyalty, shall be maintained through extrinsic motivations where some rewards and incentives can be offered to students to more actively engage on SM. According to Keitzmann et al (2012), both intrinsic and extrinsic motivational factors are important in motivating active content sharing and engagement on SM. 
Factors limiting optimal students' engagement on Social Media: A study of Higher Education ...

Lastly, customer advocacy, which is a stage where customers become brand advocates on SM, by sharing their experiences and stories with other customers, seems to be affected due to a fearful attitude of students towards official SM accounts. According to some students, they are unable to share their experiences, stories and feedback more openly on SM due to fear of being targeted by their HEIs for candid informal view. This factor is also linked with the level of informality on SM where they feel that their style or way of writing or communicating content will not match the formal communication style adopted by their HEIs on SM. Here it is important for HEIs to adopt a more active listening in mode of SM pages, which are actively being followed by students, to understand their crowd cultures (Holt, 2016). This can educate them about content preference and communication tone preference of students on SM. Such knowledge will enable HEIs to create a SM environment that is more relevant to students and encourages them to actively participate and co-create value on SM.

\section{Conclusion}

Findings of this study have enabled identifying negative elements associated with SM based communication that are believed to negatively influence students' engagement on SM. There are several studies highlighting actions to be taken (do's) to enhance the customer engagement on SM (Riley, 2020; Alalwan, et al., 2020; Lei, Pratt, \& Wang, 2017; Jayasingh \& R.Venkatesh, 2015) but there was dearth of research to explain don'ts of SM based communication. This study has therefore filled this theoretical gap for SM based marketing communication, making HEIs more aware regarding do's and don'ts of SM marketing communication. Further findings of this study have provided information to HEIs regarding their content strategy on SM by identifying content related matters that are believed to affect students' satisfaction level while engaging with their HEIs on SM. By having this insight, HEIs can plan their SM content strategy accordingly to remove any barriers that are hindering students' engagement on SM. Non-content related matters also provide HEIs important information regarding their practices relating to SM based communication and avoid actions that are not aligned with crowd cultures of their SM pages.

\section{References}

Alalwan, A. A., Algharabat, R. S., Baabdullah, A. M., Rana, N. P., Qasem, Z., \& Dwivedi, Y. K. (2020). Examining the impact of mobile interactivity on customer engagement in the context of mobile shopping. Journal of Enterprise Information Management, 33(3), 627-653. https://doi.org/10.1108/JEIM-07-2019-0194

Ali, D. \& Xiaoying, L. (2021). The influence of content and non-content cues of tourism information quality on the creation of destination image in social media: A study of Khyber Pakhtunkhwa, Pakistan. Liberal Arts and Social Sciences International Journal (LASSIJ), 5(1), 245-265. https://doi.org/10.47264/idea.lassij/5.1.17

Athukorala, A. (2018). Factors Affecting Use of Social Media by University Students: A Study at Wuhan University of China. Journal of the University Librarians Association of Sri Lanka, 21(2), 44-72. https://doi.org/10.4038/jula.v21i2.7917

Batool, S., Iftikar, M., \& Mashal, A. (2020). Visual Metaphors in Pakistani Television Commercials: Its Role in Shaping Female Consumer's Perceptions about Brand Image and its Consumption. Liberal Arts and Social Sciences International Journal (LASSIJ), 4(2), 145-158. https://doi.org/10.47264/idea.lassij/4.2.12 
Dabner, N. (2012). Breaking Ground' in the use of social media: A case study of a university earthquake response to inform educational design with Facebook. Social Media in Higher Education, 15(1), 69-78. https://doi.org/10.1016/j.iheduc.2011.06.001

Denzin, N. K., \& Lincoln, Y. S. (2005). Qualitative Research. Sage Publishing.

Eagleman, A. N. (2013). Acceptance, motivations, and usage of social media as a marketing communications tool amongst employees of sport national governing bodies. Sport Management Review, 16(4), 488-497. https://doi.org/10.1016/j.smr.2013.03.004

Farook, F. S., \& Abeysekara, N. (2016). Influence of Social Media Marketing on Customer Engagement. International Journal of Business and Management Invention, 5(12), 115125.

Habibi, M. R., Larochea, M., \& Richard, M.-O. (2014). Brand communities based in social media: How unique are they? Evidence from two exemplary brand communities. International Journal of Information Management, 34, 123-132. https://doi.org/10.1016/j.ijinfomgt.2013.11.010

Haenfler, R. (2013). Subcultures: The Basics. Routledge.

Hanna, R., Rohm, A., \& Crittenden, V. L. (2011). We're all connected: The power of the social media ecosystem. Business Horizons, 54 , 265-273. https://doi.org/10.1016/j.bushor.2011.01.007

Hansen, D., Shneiderman, B., \& Smith, M. A. (2011). Analyzing social media networks with NodeXL: Insights from a connected world. Elsevier.

Hoffman, D., \& Fodor, M. (2010). Can You Measure the ROI of Your Social Media Marketing? MIT Sloan Management Review, 52(1), 41-49. https://sloanreview.mit.edu/article/can-you-measure-the-roi-of-your-social-mediamarketing/

Holt, D. (2016, March). Branding in the Age of Social Media. Harvard Business Review. https://hbr.org/2016/03/branding-in-the-age-of-social-media

Hudson, S., \& Thal, K. (2013). The impact of social media on the consumer decision process: Implications for tourism marketing. Journal of Travel \& Tourism Marketing, 30, 156160. https://doi.org/10.1080/10548408.2013.751276

Jacobson, J., Gruzd, A., \& Hernández-García, Á. (2020). Social media marketing: Who is watching the watchers?. Journal of Retailing and Consumer Services, 53, 1-12. https://doi.org/10.1016/j.jretconser.2019.03.001

Jayasingh, S., \& Venkatesh, R. (2015). Customer Engagement Factors in Facebook Brand Pages. Asian Social Science, 11(26), 19-29. https://doi.org/10.5539/ass.v11n26p19

Keitzmann, J. H., Hermkens, K., McCarthy, I. P., \& Silvestre, B. S. (2011). Social media? Get serious! Understanding the functional building blocks of social media. Business Horizons, 54, 241-251. https://doi.org/10.1016/j.bushor.2011.01.005

Keitzmann, J. H., Silvestre, B., McCarthy, I., \& Pitt, L. (2012). Unpacking the Social Media Phenomenon: towards a research agenda. Journal of Public Affairs, 10(2), 109-119. https://doi.org/10.1002/pa.1412

Kim, A. J., \& Ko, E. (2010). Impacts of Luxury Fashion Brand's Social Media Marketing on Customer Relationship and Purchase Intention. Journal of Global Fashion Marketing, 1(3), 164-171.

Lagrosen, S. O., \& Grunden, K. (2014). Social media marketing in the wellness industry. The TQM Journal, 253 - 260. https://doi.org/10.1108/TQM-12-2013-0129

Lagrosen, S., \& Josefsson, P. (2011). Social media marketing as an entrepreneurial learning process. International Journal of Technology Marketing, 6(4), 331-340. 
Factors limiting optimal students' engagement on Social Media: A study of Higher Education ...

Laroche, M., Habibi, M. R., Richard, M. O., \& Sankaranarayanan, R. (2012). The effects of social media based brand communities on brand community markers, value creation practices, brand trust and brand loyalty. Computers in Human Behavior, 28(5), 17551767. https://doi.org/10.1016/j.chb.2012.04.016

Lei, S. S., Pratt, S., \& Wang, D. (2017). Factors influencing customer engagement with branded content in the social network sites of integrated resorts. Asia Pacific Journal of Tourism Research, 22(3), 316-328.

McCarthy, J., Rowley, J., Ashworth, C. J., \& Pioch, E. (2014). Managing brand presence through social media: the case of UK football clubs. Internet Research, 181 - 204. https://doi.org/10.1108/IntR-08-2012-0154

McKeon, R. (1973). Introduction to Aristotle. University of Chicago.

Mehmood, M. A., Aftab, F., \& Mushtaq, H. (2016). Role of Social Media Marketing in HEIs Admission. Journal of Business Studies, 12(2), 137-152.

Mehmood, M. A., Janjua, Q. R., \& Saeed, M. A. (2021). Management of Social Media Marketing by Higher Education Institutes. Pakistan Social Sciences Review, 5(4), 88104. https:/doi.org/10.35484/pssr.2021(5-IV)07

Mehmood, M. A., Janjua, Q. R., Akram, M., Laeeque, S. H., \& Aftab, F. (2021). Factors Influencing HEIs to Adopt Social Media as a Marketing Communication Tool. Journal of Marketing Strategies, 3(3), 132-154. https://doi.org/10.52633/jms.v3i3.124

Mehreen, K., Roshan, R., \& Gul, M. (2020). Psychological Factors Influencing the Adoption of Web-Based Shopping Behaviour of Female Consumers. Liberal Arts and Social Sciences International Journal (LASSIJ), 3(2), 169-184. https://doi.org/10.47264/idea.lassij/3.2.19

Michaelidou, N., Siamagka, N. T., \& Christodoulides, G. (2011). Usage, barriers and measurement of social media marketing: An exploratory investigation of small and medium B2B brands. Industrial marketing management, 40(7), 1153-1159.

Mingers, J., \& Willcocks, L. (2017). An integrative semiotic methodology for IS research. Information and Organization, 27(1), 17-36.

Molenaar, A., Saw, W. Y., Brennan, L., Reid, M., Lim, M. S., \& McCaffrey, T. A. (2021). Effects of Advertising: A Qualitative Analysis of Young Adults' Engagement with Social Media About Food. Nutrients, 13(6), 1934, 1-18.

Muniz, A., \& O'Guinn, T. C. (2001). Brand Community. Journal of Consumer Research, 27(4), 412-432.

Nadaraja, R., \& Yazdanifard, R. (2013). Social media marketing: advantages and disadvantages. Center of Southern New Hempshire University, 1-10.

Qureshi, U. (2016, 09 27). Pakistan Facebook Users crosses the landmark of 25 Million users. Umair Qureshi.com. Pakistan. http://umairqureshi.com/pakistan-deepens-facebookuser-base-with-over-11-million-users/

Razak, S. A., \& Latip, N. A. B. M. (2016). Factors that influence the usage of social media in marketing. Journal of Research in Business and Management, 4(2), 1-7.

Rideout, V., \& Fox, S. (2018). Digital Health Practices, Social Media Use, and Mental WellBeing Among Teens and Young Adults in the U.S. Hopelab \& Well Being Trust.

Riley, J. (2020). Sustaining customer engagement through social media brand communities. Journal of Global Scholars of Marketing Science, 30(4), 344-357.

Santini, F. d., Ladeira, W. J., Pinto, D. C., Herter, M. M., Sampaio, C. H., \& Babin, B. J. (2020). Customer engagement in social media: a framework and meta-analysis. Journal of the Academy of Marketing Science, 48, 1211-1228. 
Sashi, C. (2012). Customer engagement, buyer-seller relationships, and social media. Management Decision, 50(2), 253-272. https://doi.org/10.1108/00251741211203551

Shawky, S., Kubacki, K., Dietrich, T., \& Weaven, S. (2020). A dynamic framework for managing customer engagement on social media. Journal of Business Research, 121, 567-577. https://doi.org/10.1016/j.jbusres.2020.03.030

Sigala, M. (2009). E-service quality and Web 2.0: expanding quality models to include customer participation and inter-customer support. The Service Industries Journal, 29(10), 1341-1358.

Stephen, A. T. (2016). The role of digital and social media marketing in consumer behavior. Current Opinión in Psychology, 10, 17-21. https://doi.org/10.1016/j.copsyc.2015.10.016

Suhail, S. (2019, 9 12). 10\% of Pakistanis Connected to the Internet; $50 \%$ of Those are on Mobiles. https://pakwired.com/internet-users-in-pakistan/

Tiago, M. T., \& Verı'ssimo, J. M. (2014). Digital marketing and social media: Why bother? Business Horizons, 57(6), 703-708. https://doi.org/10.1016/j.bushor.2014.07.002

Tsimonis, G., \& Dimitriadis, S. (2014). Brand strategies in social media. Marketing Intelligence \& Planning, 328-344. https://doi.org/10.1108/MIP-04-2013-0056

Wind, J., \& Mahajan, V. (2002). Digital Marketing. Emerging Issues in Management, 1 , 4354.

Xiong, L., Alsadoon, A., Maag, A., Prasad, P. W. C., Hoe, L. S., \& Elchouemi, A. (2018, August). Rise of social media marketing: A perspective on higher education. In 2018 $13^{\text {th }}$ International Conference on Computer Science \& Education (ICCSE) (pp. 1-6). IEEE.

Zollo, L., Filieri, R., Rialti, R., \& Yoon, S. (2020). Unpacking the relationship between social media marketing and brand equity: The mediating role of consumers' benefits and experience. Journal of Business Research, 117, 256-267. https://doi.org/10.1016/j.jbusres.2020.05.001 